\title{
PRIMARY REPAIR MINIMIZING THE USE OF CONDUITS IN NEONATES AND INFANTS WITH TETRALOGY OR DOUBLE-OUTLET RIGHT VENTRICLE AND ANOMALOUS CORONARY ARTERIES
}

Christo I. Tchervenkov, MDa

Marc P. Pelletier, MDa

Dominique Shum-Tim, MD

Marie J. Béland, MD $^{\mathrm{b}}$

Charles Rohlicek, $\mathrm{MD}^{\mathrm{b}}$
Objective: The purpose of this study was to review our results with an approach of early primary repair for tetralogy of Fallot or double-outlet right ventricle with anomalous coronary arteries, using several techniques to minimize the use of a conduit. Methods: Twenty consecutive neonates and infants with anomalous coronary arteries crossing an obstructed right ventricular outflow tract underwent primary repair. Median age was 5.5 months and mean weight $6.22 \mathrm{~kg}$. The anomalous coronary arteries included the left anterior descending from the right coronary artery $(n=10)$, the right coronary artery from the left anterior descending $(n=1)$, the left anterior descending from the right sinus $(n=1)$, and a significant conal branch from the right coronary artery (n $=7)$ or left anterior descending $(n=1)$. Two neonates had pulmonary atresia. The right ventricular outflow tract was reconstructed without a conduit in 18 patients, including those with pulmonary atresia. Surgical techniques included main pulmonary artery translocation in 4 patients, transannular repair under a mobilized left anterior descending coronary artery in 2 patients, and displaced ventriculotomy with subcoronary suture lines in 8 patients. In 4 patients the right ventricular outflow tract was repaired via the ventriculotomy and/or pulmonary arteriotomy. A homograft was used as the sole right ventricle-pulmonary artery connection in 1 patient and in another a homograft was added to a hypoplastic native pathway. Results: There have been no early or late deaths. The right ventricular/left ventricular pressure ratio within 48 hours of the operation was $0.47 \pm 0.10$. There were 2 reoperations at 8 and 11 years after the operation, during a mean follow-up of 5.2 years (1-11.3 years). Conclusions: Primary repair of tetralogy of Fallot or double-outlet right ventricle with anomalous coronary arteries can be done in neonates and infants with excellent results. Alternative surgical techniques for right ventricular outflow tract reconstruction, such as main pulmonary artery translocation, can avoid the use of a conduit in most patients. (J Thorac Cardiovasc Surg 2000;119:314-23)
T he incidence of coronary artery anomalies in tetralogy of Fallot (TOF) is reported to be $2 \%$ to $10 \%$. $^{1-6}$ Surgical repair in the presence of an anomalous coronary artery across an obstructed and hypoplastic right ventricular outflow tract (RVOT) presents a significant

From the Division of Cardiovascular Surgery and the Division of Cardiology, ${ }^{\mathrm{b}}$ The Montreal Children's Hospital, McGill University Health Center, Montreal, Quebec, Canada.

Read at the Twenty-fifth Annual Meeting of The Western Thoracic Surgical Association, Olympic Valley (Lake Tahoe), Calif, June 23-26, 1999.

Received for publication June 29, 1999; revisions requested July 19, 1999; revisions received Sept 22, 1999; accepted for publication Sept 23, 1999. surgical challenge and has been associated with increased operative morbidity and mortality. ${ }^{3,7}$ This has led some to consider such a combination of lesions as a contraindication to primary repair in early life, recommending instead initial palliation. ${ }^{8,9}$ The widespread

\footnotetext{
Address for reprints: Christo I. Tchervenkov, MD, Director, Cardiovascular Surgery, The Montreal Children's Hospital, Room C829, 2300 Tupper St, Montreal, Quebec, Canada H3H 1P3.
}

Copyright $\odot 2000$ by Mosby, Inc.

$0022-5223 / 2000 \$ 12.00+0 \quad \mathbf{1 2 / 6 / 1 0 3 3 0 6}$ 

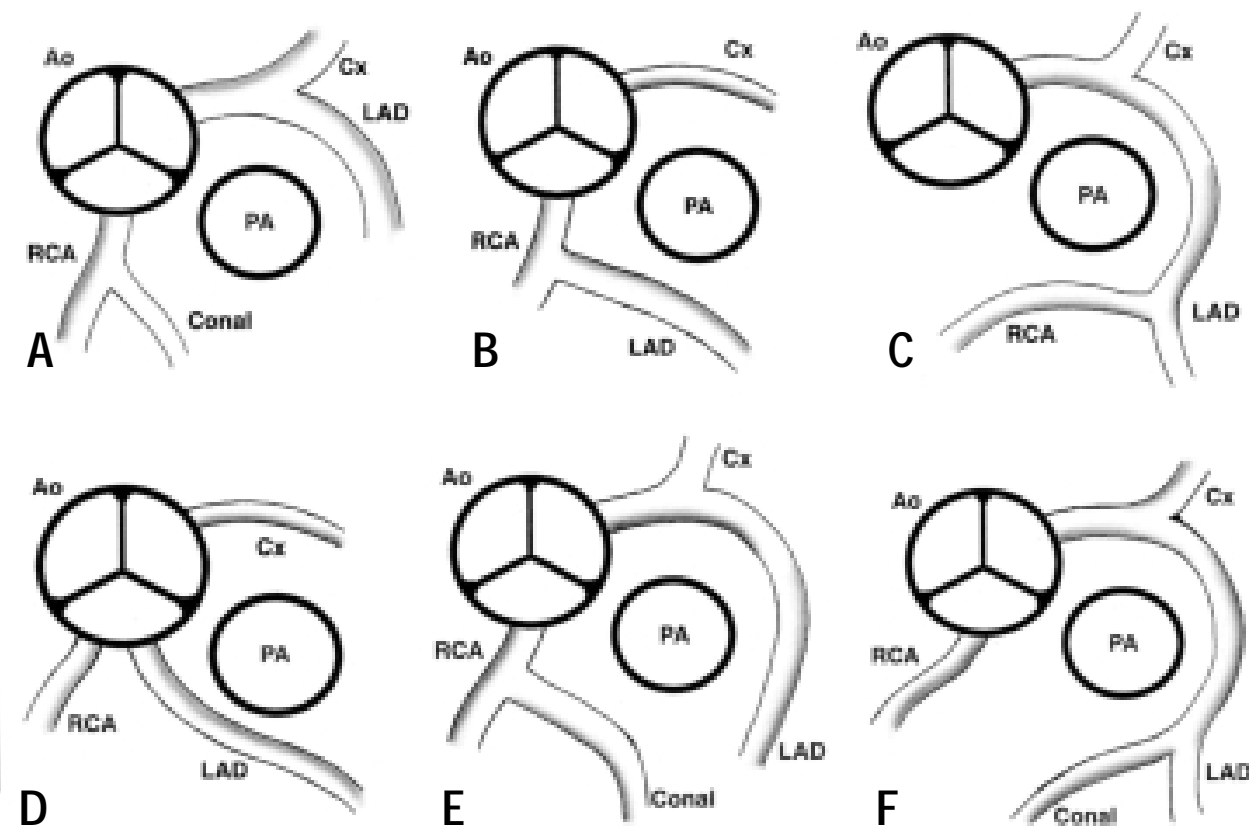

Fig 1. Anatomy of anomalous coronary arteries in 20 patients with RVOT obstruction. A, Normal coronary anatomy in TOF; B, LAD from RCA $(\mathrm{n}=10)$; $\mathbf{C}$, RCA from LAD $(\mathrm{n}=1)$; $\mathbf{D}$, LAD from right coronary sinus $(\mathrm{n}=1)$; $\mathbf{E}$, large conal branch from RCA $(\mathrm{n}=7) ; \mathbf{F}$, large conal branch from LAD $(\mathrm{n}=1)$. $C x$, Circumflex; $A o$, aorta; $P A$, pulmonary artery.

use of this conservative approach can be inferred by the absence of surgical series in the literature dealing with repair of these conditions in the neonatal period and in early infancy.

At Montreal Children's Hospital we adopted in 1987 an institutional policy of early primary repair for all patients with TOF regardless of age, weight, or pulmonary artery size. Since then, no patient with TOF has received a shunt at our institution. This policy has also been used in patients with double-outlet right ventricle (DORV). It was only natural for us to consider early primary repair for patients with coronary anomalies as well.

In this report we review our results of early primary repair in neonates and infants with TOF or DORV and anomalous coronary arteries crossing an obstructed RVOT, using several surgical techniques to avoid the use of a conduit.

\section{Patients and methods}

Patient population. From 1988 to 1998, 20 patients with the diagnosis of either TOF or DORV, who had not previously undergone operation, were found to have an anomalous coronary artery crossing an obstructed RVOT. There were 11 male and 9 female patients. All patients were referred before age 1 year. The median age at time of repair was 5.5 months
(6 days-15 months) and the mean weight was $6.22 \mathrm{~kg}$ (2.56$11.5 \mathrm{~kg}$ ). Of the 10 patients younger than 6 months old, 5 were neonates. There has also been a trend toward earlier repair with time. Thus the median age of the 10 patients operated on between 1988 and 1993 was 8 months (6 days-15 months), whereas for the 10 patients operated on between 1994 and 1998, the median age was only 3 months (11 days-12 months). Fourteen patients had TOF, 5 had DORV with subaortic ventricular septal defect (VSD), and 1 patient had DORV with a doubly committed VSD. In the presence of RVOT obstruction, patients were considered to have DORV only if there was aortic overriding of at least $90 \%$ in the presence of aortic mitral continuity or a greater than $50 \%$ override in the presence of aortic mitral discontinuity. ${ }^{10}$ Patients in whom these criteria were not fulfilled were considered to have TOF. In 4 patients with DORV, the VSD was restrictive. Two neonates with TOF also had pulmonary atresia with the main pulmonary artery (MPA) present. Patients with pulmonary atresia and absence of the MPA were excluded from this review because of the impossibility of avoiding a conduit.

All patients had an anomalous coronary artery crossing the RVOT. This was defined as a coronary artery whose location interfered with the usual surgical repair of the obstructed RVOT and whose sacrifice would seriously compromise the viability of a significant portion of myocardium. ${ }^{2}$ The coronary anomalies encountered are illustrated in Fig 1. They consisted of the following: left anterior descending artery 

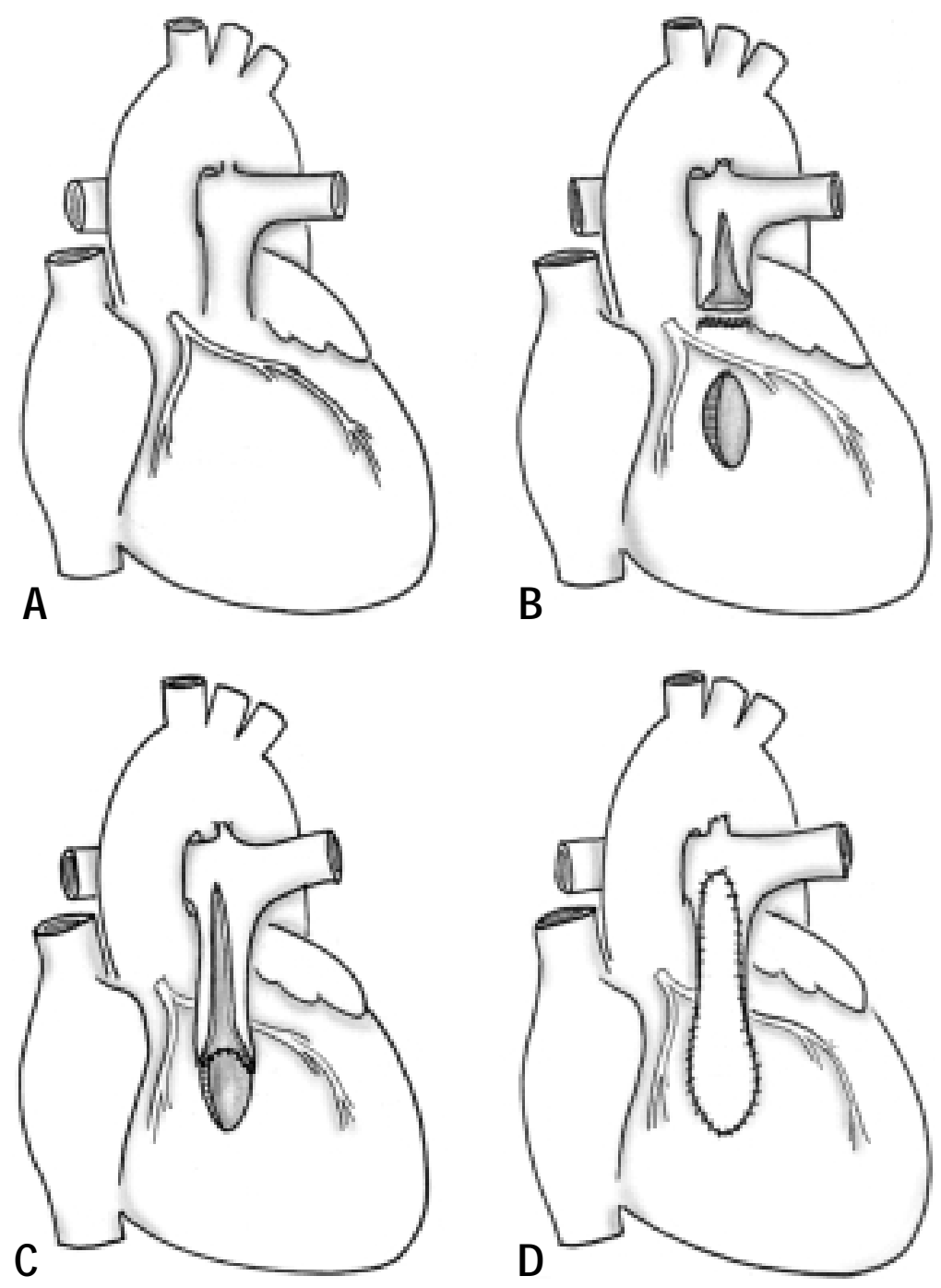

Fig 2. Technique of MPA translocation.

(LAD) from right coronary artery (RCA) $(\mathrm{n}=10)$, RCA from LAD $(n=1)$, LAD from right coronary sinus $(n=1)$, large conal branch from RCA $(n=7)$, and large conal branch from LAD $(n=1)$. Large conal branches were considered significant when they were of similar caliber to or larger than the LAD and coursed down the entire length of the anterior right ventricular wall toward the interventricular septum. In fact, some of these represented a dual LAD system. Their preservation was believed to be essential for myocardial function.

The indications for operation were as follows: 4 patients had ductus-dependent pulmonary circulation, 1 had a persistent hypercyanotic spell, 7 had a history of hypercyanotic spells, 2 had increasing cyanosis, and 6 were free of symptoms. Although preoperative echocardiography was done routinely in all patients, angiography was obtained in only 9 patients earlier in the series. This was because of a change in policy at our institution since 1994 such that routine cardiac catheterization in TOF or DORV was no longer done. The coronary anomaly was suspected or identified preoperatively in 9 of 20 patients, by either echocardiography or angiography. Of the 11 patients in whom an anomalous vessel was not suspected, 4 had undergone a preoperative cardiac catheterization.

Operative techniques. No patient received a systemic pulmonary shunt because of the anomalous coronary artery and all lesions were repaired at the initial operation. This was accomplished through a median sternotomy with standard cardiopulmonary bypass support after aortic and bicaval cannulation. The mean bypass time was 144.4 minutes (93-236 minutes). The mean crossclamp time was 76.4 minutes (35150 minutes). Deep hypothermic circulatory arrest, although used in 7 of 10 patients from 1988 through 1993, was used in only 2 of the last 10 patients since 1994 . All patients were cooled to reach an average lowest temperature of $16.8^{\circ} \mathrm{C} \pm$ 

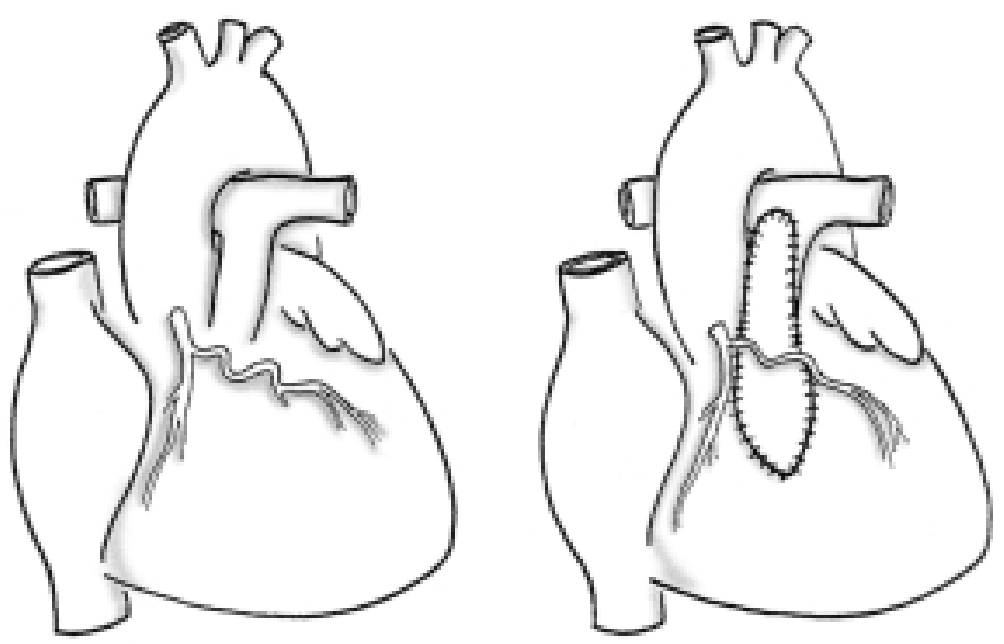

Fig 3. Technique of transannular repair under a mobilized coronary artery.

$1.8^{\circ} \mathrm{C}$ in patients undergoing circulatory arrest and $21.9^{\circ} \mathrm{C} \pm$ $3.3^{\circ} \mathrm{C}$ in patients operated on with bypass only. Myocardial protection was provided by a single dose of crystalloid cardioplegic solution.

VSD closure. In all patients, a right ventriculotomy incision was made. In some patients, the ventriculotomy was displaced to either the left or right to avoid damage to the anomalous coronary artery. Furthermore, the ventriculotomy was frequently made obliquely rather than vertically for the same reason. The VSD was closed with a polytetrafluoroethylene patch $^{*}$ with either interrupted 5-0 Ethibond pledget-supported sutures or a running 5-0 Prolene polypropylene suture (Ethicon, Inc, Somerville, NJ). This was done after the necessary relief of the RVOT obstruction was accomplished by incising and resecting the hypertrophic muscle bundles usually both in the septal and the parietal extension of the conal septum. In 4 of the 6 patients with DORV, the VSD was restrictive and was first enlarged by resection of a triangular portion of the interventricular septum leftward and anteriorly. Intraventricular rerouting was done with a generous elongated polytetrafluoroethylene patch. This was necessary to avoid subaortic obstruction.

RVOT reconstruction. The type of surgical reconstruction of the RVOT done in each patient was individualized according to the anatomy in the case. It is not our policy to use monocusp valves in any of our TOF or DORV repairs and none were used in this series. Several surgical techniques were performed to avoid the use of a conduit, which was achieved in 18 of the 20 patients. A number of factors determined the surgical technique used. The two most important were the location and course of the anomalous coronary artery and the size of the pulmonary valve anulus. If the pulmonary valve anulus was normal or near normal size, obviat-

${ }^{*}$ Gore-Tex polytetrafluoroethylene patch. Gore-Tex is a registered trademark of W. L. Gore \& Associates, Inc, Flagstaff, Ariz. ing the need for a transannular patch, the relief of RVOT obstruction was accomplished via a ventriculotomy located to avoid injury to the anomalous coronary artery with or without a pulmonary arteriotomy incision. When the pulmonary valve anulus was hypoplastic, necessitating a transannular patch, the presence of an anomalous coronary artery across the site of intended reconstruction necessitated the use of one of several surgical techniques to avoid a conduit.

MPA translocation. We first used this technique in 1990, and it was subsequently reported by O'Blenes, Freedom, and Coles ${ }^{11}$ in 1996, who used it in a 3-year-old patient. Although O'Blenes, Freedom, and Coles ${ }^{11}$ used the technique described by Lecompte and coworkers ${ }^{12}$ to bring the pulmonary arteries in front of the aorta, we have not found it desirable to perform the Lecompte maneuver with severely hypoplastic pulmonary arteries in front of a very large ascending aorta. The technique was used in patients requiring a transannular patch in whom the aberrant coronary artery crossed the severely hypoplastic RVOT at or near the pulmonary valve anulus (Fig 2). After mobilization of the MPA and the right and left pulmonary arteries and division of the ductus arteriosus, the MPA was divided just distal to the anulus. The proximal end was oversewn. The distal end was then translocated onto the right ventriculotomy site anterior to the aberrant coronary artery, reconstituting their normal relationship. Half the circumference of the divided MPA was then sutured to the ventriculotomy incision. The anterior wall of the MPA was then opened longitudinally to allow for the appropriate enlargement. The incision could be extended onto the left pulmonary artery in the presence of left pulmonary artery stenosis. After closure of the VSD, the opened pulmonary artery and ventriculotomy incisions were augmented with an autologous transannular pericardial patch. This technique was used in 4 patients.

$R V O T$ reconstruction under a mobilized LAD. This surgical technique was similar to the method previously described by 


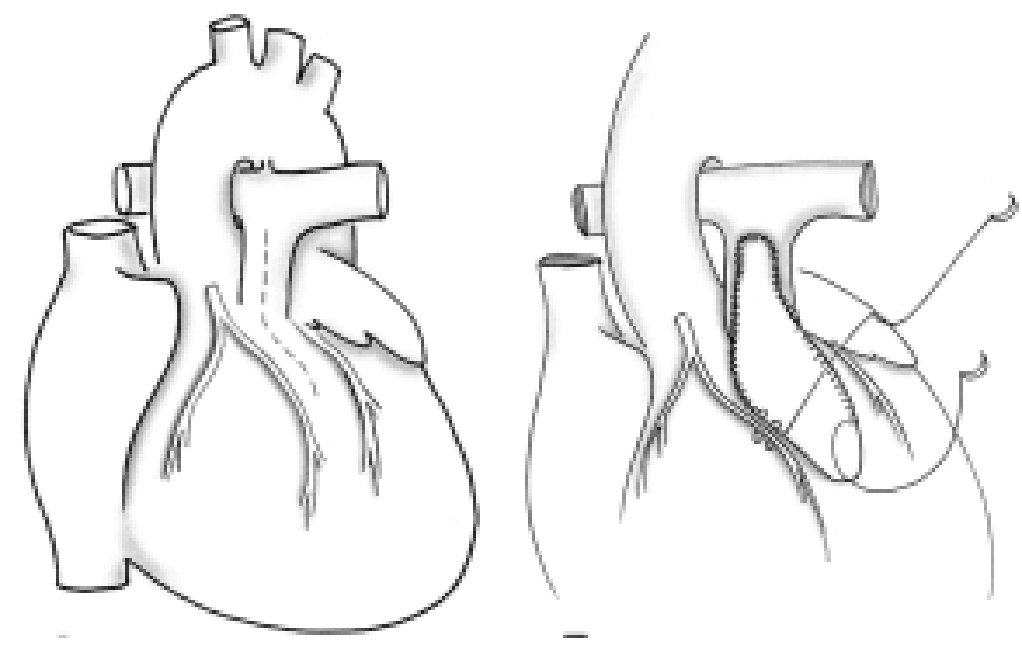

Fig 4. Technique of displaced transannular ventriculotomy incision with subcoronary suture lines.

Bonchek. ${ }^{13}$ It was used if the aberrant coronary artery was unusually tortuous, allowing its mobilization and the placement of a transannular patch underneath (Fig 3). The coronary artery was mobilized together with surrounding epicardium and underlying myocardium. Great care was used not to denude the coronary artery. In addition, the transannular pericardial patch was slightly undersized, to avoid stretching and compression of the coronary artery. This technique was used in 1 neonate with TOF and valvular pulmonary atresia and in another 5-week-old infant with DORV and severe hypoplasia of the pulmonary valve anulus. In both patients the LAD was tortuous and crossed the RVOT below the anulus of the pulmonary valve.

Displaced ventriculotomy and subcoronary suture lines. In 8 patients, the aberrant coronary artery traveled an oblique course below the pulmonary valve anulus. The transannular incision was extended into the ventricle in an oblique fashion, displaced from its usual location and coursed along the anomalous vessel. In the case of a large conal branch, the space between it and the LAD was often rather narrow. To avoid injury to this vessel, closure of the ventriculotomy was achieved with a subcoronary suture line (Fig 4). A continuous U-shaped suture line progressed from the pericardial patch, going under the coronary artery, and coming out lateral to it into epicardium. Then the suture was brought back from epicardium to endocardium under the anomalous coronary artery and coming through the pericardial patch, thus preserving the coronary artery on an island of myocardium. Occasionally this subcoronary suture line was reinforced with interrupted pledget-supported subcoronary horizontal mattress sutures.

Ventriculotomy and pulmonary arteriotomy without conduit. In 4 patients, a transannular patch was not required because the pulmonary valve anulus was adequate. Adequate RVOT reconstruction could be accomplished through a ventriculotomy and/or pulmonary arteriotomy, in addition to resection of hypertrophic and malaligned muscular bundles.

Pulmonary homograft conduit. In 2 patients, a pulmonary homograft conduit was required to achieve an adequate RVOT. In 1 patient, the conduit (15-mm homograft) served as the sole right ventricular-pulmonary artery connection. In the second patient, an 11-mm homograft was added as an accessory pathway, after a pulmonary valvotomy, because the native RVOT was judged to be too small to act as the sole right ventricular-pulmonary artery pathway. We hope that, with time, the native pathway will enlarge adequately, thus rendering a future conduit change unnecessary. Both patients requiring a conduit had an LAD arising from the RCA.

Patient follow-up. Follow-up was obtained for all patients through clinic visits and cardiology appointments. Mean follow-up was 5.2 years (1-11.3 years), with the follow-up period ending on May 31, 1999. All patients have therefore been followed up for at least 1 year.

Statistics. Results are expressed as mean or median \pm standard deviation. Data were analyzed with the InStat program (GraphPad Software, Inc, San Diego, Calif), using a paired nonparametric test when appropriate.

\section{Results}

All patients underwent primary repair and no patient received a palliative shunt. The intraoperative right ventricular/left ventricular pressure ratio was $0.59 \pm$ 0.15 at completion of the operation. Within 48 hours of the operation, the right ventricular/left ventricular pressure ratio decreased to $0.47 \pm 0.10(P<.01)$. There was no early or late mortality. Two patients underwent reoperation at 8 and 11 years after the initial operation, respectively, during a mean follow-up of 5.2 years (range 1-11.3 years). The reoperation in the first patient was done because of stenosis at the pulmonary artery 
bifurcation and in the second because of a residual atrial septal defect.

Only 2 patients required a conduit. In 1 patient, a 15$\mathrm{mm}$ pulmonary homograft was used for the construction of an RVOT at age 1 year. An anomalous LAD had been identified preoperatively by cardiac catheterization, but at operation no other technique could be used. This patient has been followed up for nearly 5 years and remains free of symptoms, with a right ventricle-MPA gradient of $25 \mathrm{~mm} \mathrm{Hg}$. In the second patient, an 11-mm pulmonary homograft was added to the native RVOT after resection because the pulmonary valve anulus was believed to be inadequate. This patient has also been free of symptoms in the intermediate postoperative period.

Angiographic follow-up was obtained in 9 of 20 patients. Apart from the previously mentioned reoperations, only 1 other patient demonstrated a significant stenosis of the left pulmonary artery, which was treated by percutaneous stenting 47 months after the operation with a good result. This patient had undergone repair via a displaced ventriculotomy and subcoronary suture lines with a transannular patch. Intraoperative right and left pulmonary artery sizes were 8 and $7 \mathrm{~mm}$, respectively. Angiography had demonstrated a stenosed left pulmonary artery with a $40 \mathrm{~mm} \mathrm{Hg}$ gradient. This patient is now clinically free of symptoms at 4 years after stent placement and 8 years after surgical repair. The remaining 6 patients had no evidence of significant RVOT gradients or abnormalities on cardiac catheterization. All patients (20/20) were clinically free of symptoms at last contact.

\section{Discussion}

There has been a tremendous change in the surgical treatment of congenital heart disease in the past 20 years in favor of early primary repair for the vast majority of cardiac malformations. Repair of TOF has been at the forefront of this transformation. ${ }^{9}$ Encouraged by this favorable experience, the approach of early primary repair has also been extended to more complex lesions, such as DORV, with excellent results. ${ }^{10}$ This approach has been motivated by the desirability of establishing normal anatomic and physiologic conditions as early in life as possible, to avoid the undesirable long-term effects of unrepaired congenital heart disease, as well as to avoid the complications of palliative operations and the risk of multiple operations. ${ }^{14,15}$ Despite this, the presence of an anomalous coronary artery crossing an obstructed outflow tract has traditionally been considered to be a contraindication to primary repair in infancy. ${ }^{8,9}$ This is mostly because of the morbidity and mortality associated with this condition during complete cardiac repair when one needs to enlarge the RVOT, ${ }^{3,6,7}$ because of the possibility of injury to the anomalous vessel. ${ }^{16}$ Another argument in favor of a palliative approach in infancy has been the desire to avoid the placement of a small conduit in a baby.

Before this decade there were only 5 surgical series dealing with repair of TOF and anomalous coronaries. Berry and McGoon ${ }^{7}$ reported in 1973 the Mayo Clinic experience with 27 patients aged 2 to 29 years, in which there was a $30 \%$ mortality rate. Most deaths were a result of injury to the anomalous coronary, which caused a myocardial infarction. Meyer and associates $^{4}$ reported in 1975 their experience in Houston with 23 patients, in which there was an $8.7 \%$ mortality rate, as a result of injury to the anomalous coronary artery. Hurwitz and colleagues ${ }^{2}$ reported in 1980 their experience with 25 children, in which there was an $8 \%$ mortality rate. In 1987 Humes and coworkers ${ }^{3}$ updated the Mayo Clinic experience with 20 new patients and a $15 \%$ mortality rate. Previous palliation was used in $60 \%$ of these patients. Finally, Landolt and associates ${ }^{17}$ reported no mortality among 9 of 11 patients undergoing repair, with 2 infants undergoing palliation. Of significance is that both patients in whom the anomalous coronary artery was injured, and successfully repaired, survived the operation.

Although these surgical series belong to another era of cardiac surgery, a number of conclusions can be drawn from them. Most of the mortality appears to be a result of either injury to the anomalous coronary artery or significant residual RVOT obstruction. These were operations done in children, teenagers, or even young adults. Although it is not clear from the three oldest series how many patients initially received palliation, it must have been a significant number inasmuch as the age at operation was quite old. ${ }^{2,4,7}$ It is also unclear what the true denominator in this patient population really was and what would have happened to patients with extreme hypoplasia of the RVOT in the presence of anomalous coronaries. It is clear that no repairs were undertaken in early life. Putting that aside, it is remarkable how few of these patients required the placement of a conduit between the right ventricle and the pulmonary artery.

The only surgical series in the current era was reported in 1998 by Brizard and associates ${ }^{5}$ from the Royal Children's Hospital in Melbourne. They undertook repair in 36 patients with TOF and anomalous coronaries at a median age of 23 months (2.8-170 months) and weight of $9.9 \mathrm{~kg}(5.2-41 \mathrm{~kg})$, with no early or late mor- 
tality. Previous palliation, however, was used in 20 patients (56\%). Of importance is the consistent use of a transatrial-transpulmonary approach with limited transannular patch if necessary, reducing the use of right ventricular-pulmonary artery conduits to only 2 patients. Although these results are remarkable, it does not appear that this surgical technique can be used consistently in the neonate or young infant. Despite increasing tendency toward earlier repair, the authors recommend initial palliation in young infants of less than 4 months old unless they have exceptionally favorable anatomic characteristics.

At Montreal Children's Hospital our neonatal and infant surgery program began in 1987..$^{18-22}$ Since that time no patient with TOF or DORV of the TOF type at our institution has received a palliative shunt, with all patients referred for operation undergoing primary repair at a median age of less than 6 months. No patients have been denied repair because of age, weight, pulmonary artery size, or preoperative status. Our current policy is to proceed with repair soon after referral in patients having symptoms or to proceed with elective repair at about 3 to 4 months if the patient is free of symptoms. This aggressive approach has allowed us to get as close as possible to the true denominator in this patient population.

Our standard surgical repair of TOF uses a vertical ventriculotomy and transannular patch if the pulmonary anulus is hypoplastic. The VSD is closed via this exposure and we do not use monocusp valves in any of our repairs. In this consecutive series, we have considered the cases of patients with an anomalous coronary artery crossing an obstructed RVOT, as in TOF or DORV with a subaortic VSD. We report no early or late mortality in a consecutive series of 20 neonates and infants, with only 2 requiring a right ventricle-pulmonary artery conduit.

This series highlights our institutional philosophy of early repair, with all patients being referred at younger than 1 year old. Although operations were delayed because of nonmedical reasons in 3 patients, the median age at operation was 5.5 months, which is similar to the median age in our patients with TOF or DORV without anomalous coronary arteries. ${ }^{23}$ These results are in accordance with those of other TOF series, in which primary repair in infancy has been associated with an in-hospital mortality rate of $0 \%$ to $3 \% .^{24-27}$

From an operative standpoint, this series illustrates some of the surgical techniques available to allow RVOT reconstruction without a conduit in the presence of an anomalous coronary artery. The techniques used in $18(90 \%)$ of 20 patients in our series included translocation of the MPA, ${ }^{11}$ transannular patch under a mobilized LAD, ${ }^{13}$ displaced ventriculotomy and subcoronary suture lines, and ventriculotomy with or without pulmonary arteriotomy., ${ }^{4,5}$ Whereas most techniques have been previously described, translocation of the MPA onto the right ventricle without the Lecompte maneuver has some potential advantages in the patient with a severely hypoplastic pulmonary valve anulus. These include lower probability of RVOT obstruction or MPA stenosis, because the posterior wall of the constructed pathway consists of autogenous tissue with growth potential, and a lower probability of injury to the underlying anomalous vessel. However, despite full mobilization of the MPA and its confluent branches, this technique may not be possible if the anomalous coronary traverses the lower portion of the RVOT. In such cases, a reverse pulmonary artery flap repair over the anomalous coronary, ${ }^{15,28}$ a transannular patch repair under a mobilized LAD, or a displaced ventriculotomy and subcoronary suture lines should be considered. A conduit may be required as a last resort to allow primary repair.

The use of conduits in the infant population carries a risk of recurrent RVOT obstruction, with the need for reoperation as the child outgrows the prosthesis. It will be interesting to see whether the native pathway will grow adequately in the presence of an accessory conduit, as we have used in 1 patient, and consequently prevent future conduit changes.

The mean follow-up of more than 5 years in this study, with no early or late mortality and only two reoperations, suggests that early primary repair is appropriate in this group of patients.

\section{Conclusion}

Primary repair of TOF or DORV with anomalous coronary arteries across an obstructed RVOT can be done successfully in neonates and infants with excellent results, avoiding palliative operations and their complications. Alternative surgical techniques for RVOT reconstruction such as MPA translocation can avoid the use of a conduit in most patients. This approach is in keeping with a philosophy of early primary repair at our institution.

\section{REFERENCES}

1. Fellows KE, Freed MD, Kean JF, Van Praagh R, Bernhard WF, Castaneda AC. Results of routine preoperative coronary angiography in tetralogy of Fallot. Circulation 1975;51:561-6.

2. Hurwitz RA, Smith W, King H, Girod DA. Tetralogy of Fallot with abnormal coronary artery: 1967 to 1977 . J Thorac Cardiovasc Surg 1980;80:129-34.

3. Humes RA, Driscoll DJ, Danielson GK, Puga FJ. Tetralogy of 
Fallot with anomalous origin of left anterior descending coronary artery. J Thorac Cardiovasc Surg 1987;94:784-7.

4. Meyer J, Chiariello L, Hallman GL, Cooley DA. Coronary artery anomalies in patients with tetralogy of Fallot. J Thorac Cardiovasc Surg 1975;69:373-6.

5. Brizard CP, Mas C, Sohn YS, Cochrane AD, Karl TR. Transatrialtranspulmonary tetralogy of Fallot repair is effective in the presence of anomalous coronary arteries. J Thorac Cardiovasc Surg 1998;116:770-9.

6. Hawe A, Rastelli GC, Ritter DG, DuShane JW, McGoon DC. Management of right ventricular outflow tract in severe tetralogy of Fallot. J Thorac Cardiovasc Surg 1970;60:131-43.

7. Berry BE, McGoon DC. Total correction for tetralogy of Fallot with anomalous coronary artery. Surgery 1973;74:894-8.

8. Sullivan ID, Gooch VM. Echocardiography. In: Stark J, de Leval M, editors. Surgery for congenital heart defects. Philadelphia: WB Saunders; 1994. p. 77.

9. Castaneda AR, Jonas RA, Mayer JE Jr, Hanley FL. Tetralogy of Fallot. In: Castaneda AR, Jonas RA, Mayer JE Jr, Hanley FL, editors. Cardiac surgery of the neonate and infant. Philadelphia: WB Saunders; 1994. p. 222.

10. Tchervenkov CI, Marelli D, Béland MJ, Gibbons JE, Paquet M, Dobell ARC. Institutional experience with a protocol of early primary repair of double outlet right ventricle. Ann Thorac Surg 1995;60:S610-3.

11. O'Blenes SB, Freedom RM, Coles JG. Tetralogy of Fallot with anomalous LAD: repair without conduit. Ann Thorac Surg 1996; 62:1186-8.

12. Lecompte Y, Neveux JY, Leca F, et al. Reconstruction of the pulmonary outflow tract without prosthetic conduit. J Thorac Cardiovasc Surg 1982;84:727-33.

13. Bonchek LI. A method of outflow tract reconstruction in tetralogy of Fallot with anomalous anterior descending artery. Ann Thorac Surg 1976;21:451-3.

14. Gladman G, McGrindle BW, Williams WG, Freedom RM, Benson LN. The modified Blalock-Taussig shunt: clinical impact and morbidity in Fallot's tetralogy in the current era. J Thorac Cardiovasc Surg 1997;114:25-30.

15. van Son JAM. Repair of tetralogy of Fallot with anomalous origin of left anterior descending coronary artery. J Thorac Cardiovasc Surg 1995;110:561-2.

16. Davis JT, Teske DW, Allen HD, Cohen DM, Schauer GM. Anomalous course of the left main coronary artery in tetralogy of Fallot. Ann Thorac Surg 1996;61:229-31.

17. Landolt CC, Anderson JE, Zorn-Chelton S, Guyton RA, Hatcher CR Jr, Williams WH. Importance of coronary artery anomalies in operations for congenital heart disease. Ann Thorac Surg 1986; 41:351-5.

18. Tchervenkov CI, Paquet M, Béland M, Gibbons J, Dobell ARC. Arterial switch for transposition of the great arteries with intact ventricular septum [abstract]. Clin Invest Med 1988;11: D89.

19. Tchervenkov CI, Paquet M, Béland M, Gibbons J, Dobell ARC. Primary repair of tetralogy of Fallot in infancy [abstract]. Clin Invest Med 1989;12:C68.

20. Tchervenkov CI, Béland M, Gibbons J, Paquet M, Dobell ARC. Primary biventricular repair with extensive aortic arch reconstruction for complex congenital heart disease [abstract]. Clin Invest Med 1990;13:C47.

21. Tchervenkov CI, Béland M, Gibbons J, Paquet M, Gordon JB,
Baxter MRN, et al. Primary repair of critical congenital heart disease in early life [abstract]. Clin Invest Med 1990;13:C51.

22. Tchervenkov CI, Béland M, Gibbons J, Paquet M, Kidd WT, Dobell ARC. Repair of double outlet right ventricle (DORV) in infancy [abstract]. Can J Cardiol 1992;8(b):137b.

23. Tchervenkov CI, Quantz MA, Rohlicek C, Gibbons J, Béland MJ, Paquet M, et al. Institutional experience with early primary repair of tetralogy of Fallot [abstract]. Paper presented at the thirtieth annual meeting of the Society of Thoracic Surgeons, 1994.

24. Groh MA, Melrones JN, Bove EL, Kirklin JW, Blackstone EH, Lupinetti FM, et al. Repair of tetralogy of Fallot in infancy: effect of pulmonary artery size on outcome. Circulation 1991;84 (Suppl):III206-12.

25. Touati GD, Vouhé PR, Amodeo A, Pouard P, Mauriat P, Leca F, et al. Primary repair of tetralogy of Fallot. J Thorac Cardiovasc Surg 1990;99:396-402.

26. Stellin G, Milanesi O, Michielon G, Bianco R, Moreolo GS, Boneva R, et al. Repair of tetralogy of Fallot in the first six months of life: transatrial versus transventricular approach. Ann Thorac Surg 1995;60:S588-91.

27. Reddy VM, Liddicoat JR, McElhinney DB, Brook MM, Stanger P, Hanley FL. Routine primary repair of tetralogy of Fallot in neonates and infants less than three months of age. Ann Thorac Surg 1995;60:S592-6.

28. Dandolu BR, Baldwin SH, Norwood WI Jr, Jacobs ML. Tetralogy of Fallot with anomalous coronary artery: double outflow technique. Ann Thorac Surg 1999;67:1178-80.

\section{Discussion}

Dr John Lamberti (San Diego, Calif). The authors have performed primary repair in a complex subset of patients born with TOF or DORV and an anomalous coronary pattern. They used a variety of techniques to avoid implantation of a conduit in most of this group of patients. These patients are often treated by conduit implantation in other centers. Since the authors did use a conduit in $10 \%$ of their patients, the title of the paper should be altered or 2 patients must be deleted from the series. The basic premise of this report is still an excellent one. Congenital heart surgeons would do well to remember the authors' techniques when they encounter an anomalous coronary artery. I was not surprised to note that 4 of 11 patients thought to have normal coronary arteries had an anomalous vessel despite preoperative cardiac catheterization. We have had the same experience. A major conal branch from the RCA that appears to supply the distal LAD distribution may not be obvious on the usual views obtained during an aortic root injection in the catheterization laboratory. After the anomaly has been discovered by the surgeon, the angiogram can usually be re-read accurately. Surgeons must not assume that the coronary pattern is normal because the cardiologist says it is.

Several aspects of the proposed techniques create some concern for me personally. Four patients underwent translocation of the MPA. This operation would seem to place the right pulmonary artery on tension as it courses behind the aorta. Is there any sign of right pulmonary artery obstruction in this small subset of patients during the interim follow-up?

Dr Tchervenkov. Thank you for your kind comments. The 
reason we kept those 2 patients in the series is simply to have a consecutive series of 20 patients, not excluding anyone.

We share your concern regarding tension on the right pulmonary artery. As a matter of fact, the only patient who had the conduit as the right ventricle-pulmonary artery connection was a patient in whom we contemplated doing an MPA translocation technique. The possibility of excessive tension on the branch pulmonary arteries prevented us from using that technique. I think the MPA translocation technique can be used primarily when the anomalous coronary artery crosses either at or slightly below the hypoplastic pulmonary valve anulus. If the anomalous vessel crosses the outflow tract well below, I do not think this technique can be used safely. We have used other techniques in those situations. Of note in the literature is the technique of using a reversed flap of anterior pulmonary arterial wall to bridge over the anomalous coronary artery.

Dr Lamberti. I also am concerned about mobilizing the LAD and placing a patch beneath it. It would seem that aneurysmal dilatation of the patch might stretch the artery during long-term follow-up. Subcoronary suture lines have always made me nervous. I have used the technique on enough occasions to know that it works. Sometimes I had not planned on placing the sutures that close to the coronary artery. In long-term follow-up at 20 years, we have noted dysfunction of the free wall of the right ventricle in some of our patients in whom the outflow tract was sutured very close to a large conal or muscular coronary artery. All of your patients are described as asymptomatic. Do you have any information regarding right ventricular function or exercise testing which might suggest that the blood supply to the right or left ventricle has been compromised by these techniques?

Dr Tchervenkov. Again, those are valid concerns. Immediately on completion of the repair, all coronary arteries, particularly the anomalous ones, were full. The myocardial contractility of the region supplied by the anomalous vessel was excellent, both visually and on echocardiogram, and that has remained so at longer follow-up. We have done postoperative cardiac catheterizations in slightly less than half the patients, and the contractility appears to be well preserved. In using the technique of subcoronary suture lines, it is important to stay away from the anomalous coronary artery, perhaps about 3 to $4 \mathrm{~mm}$ away.

Dr Lamberti. All the VSDs were closed through a ventriculotomy. We have often used transatrial repair of VSD in association with limited ventriculotomy in similar patients. Have you considered transatrial patch closure of the VSD? If not, would you consider it useful in this setting?

Dr Tchervenkov. Again, this is a personal preference. In my series of TOF repairs, I have used the transatrial technique only twice in patients with a very well developed RVOT. I was not trained using that technique and therefore I have not adopted it. I am not aware of evidence on long-term follow-up that demonstrates the superiority of the transatrial approach in comparable series of patients. Is there a difference between coring out extensive myocardium from inside to adequately relieve obstruction versus making an incision in the outflow tract and raising the roof of the pathway with a lesser degree of resection on the inside? This question used to be raised by my teacher, Dr Aldo Castaneda.

Dr Lamberti. You limited the paper to primary repair and I understand that concept with regard to the title. However, did you encounter any patients with prior palliation who had the same anatomy? If so, how did you treat them and what were their outcomes?

Dr Tchervenkov. I have been impressed by the relatively longer distances that must be bridged by the various techniques in the older, previously palliated patient, when comparing two cohorts of patients- the ones from my own institution, who are referred earlier, and the ones referred from outside. In the neonate and infant those distances are extremely small, the tissues are very elastic and pliable, and it is often possible to bridge the same relative distance with greater ease than in an older child.

Dr Vaughn Starnes (Los Angeles, Calif). I have a question regarding the mean right ventricular/left ventricular ratio. You say it is 0.47 at the time of discharge. I believe the right ventricular pressure is relatively high. You call it the mean pressure, so I imagine some of them are higher, and you include pulmonary insufficiency. Have you looked at any of these ventricles by echocardiography or any other follow-up studies to search for right ventricular dysfunction, an enlarging right ventricle, relatively high pressure, and pulmonary insufficiency?

Dr Tchervenkov. The right ventricular/left ventricular pressure ratio may be slightly higher than after regular TOF repair. At 24 to 48 hours after the operation, it is in the range of 0.45 . I do not think this is unlike the ratio observed in many other series that have used different surgical techniques. The patients with some right ventricular dilatation have also had some degree of distal obstruction. You must keep in mind that our consistent approach of performing early primary repair on all patients with TOF, regardless of pulmonary artery size, age, or weight of the patient, allows us to detect all of the patients, at least in our referral area. For these reasons, we are obviously seeing a number of patients with severe distal pulmonary artery hypoplasia without necessarily distal anatomic obstruction. The distal pulmonary arterial bed is rather small, and some of these patients have had a very low Nakata index. Right ventricular function is not very easy to assess. There is also significant discrepancy between centers in the rate of pulmonary valve placement at late follow-up. We have not done an elaborate assessment, including exercise testing, in this series of patients.

Dr Starnes. Your bias is not to insert a monocusp of some variety, whether it be tissue or polytetrafluoroethylene. Is that because of concern about reoperation?

Dr Tchervenkov. I think my bias simply reflects the way I was trained by Aldo Castaneda and colleagues in Boston. They did not use a monocusp valve and had excellent results. The long-term follow-up appears to be withstanding the test of time. Our own results not using a monocusp valve are more than acceptable. There are publications comparing the use of monocusp patch versus not using one. There was 
recently a publication from Toronto that showed no difference in the degree of pulmonary regurgitation in the presence or absence of a monocusp valve. Obviously, we all have personal biases based on our training and personal experience. However, if you find that using the monocusp patch leads to a better outcome or perhaps more comfort for the surgeon, by all means use it. I am a little bit concerned that those monocusp patches may become obstructive with time, necessitating reoperation.

Dr Frank Hanley (Berkeley, Calif). I would like to comment on the issue of using right ventricular/left ventricular pressure ratios in neonates and small infants. There are some concerning misunderstandings with our continued use of this ratio. We have to remember that one of John Kirklin's many contributions was linking the right ventricular/left ventricular pressure ratio to long-term outcome. We also have to remember that those children underwent repair at several years of age, when systemic systolic pressures are in the range of 100 to $120 \mathrm{~mm} \mathrm{Hg}$. The right ventricular/left ventricular pressure ratio in this setting suggests a certain right ventricular pressure. For unclear reasons, it was decided to use this ratio rather than the absolute right ventricular pressure. Now we are performing TOF repairs in neonates and young infants, in 2.5- and 3-kg children who are still under fentanyl anesthesia and being supported with the ventilator. At the time of the pulmonary artery pressure measurement, the systemic blood pressure may be only 45 or $50 \mathrm{~mm} \mathrm{Hg}$. A right ventricular/ left ventricular pressure ratio of 0.6 in this setting sounds high, but in fact the absolute right ventricular pressure may be only $33 \mathrm{~mm} \mathrm{Hg}$. It is important to emphasize that the absolute right ventricular pressures are lower than the ratio implies.

Dr Tchervenkov. I fully endorse your comments. We have made exactly the same observation. As a matter of fact, one of the main reasons the right ventricular/left ventricular pressure ratio has fallen by 24 to 48 hours is that whereas the systemic pressure tends to rise, the right ventricular pressure remains the same and results in a more favorable ratio. We should not lose sight of the fact that some of these patients have very small distal pulmonary artery beds. Once these distal beds accept the full cardiac output, it is going to take some time before they fully develop.

\section{Availability of Journal back issues}

As a service to our subscribers, copies of back issues of The Journal of Thoracic and Cardiovascular Surgery for the preceding 5 years are maintained and are available for purchase from Mosby until inventory is depleted. The following quantity discounts are available: $25 \%$ off on quantities of 12 to 23, and one third off on quantities of 24 or more. Please write to Mosby, Inc, Subscription Services, 11830 Westline Industrial Drive, St Louis, MO 63146-3318, or call 800-453-4351 or 314-453-4351 for information on availability of particular issues and prices. If unavailable from the publisher, photocopies of complete issues may be purchased from Bell \& Howell Information and Learning, $300 \mathrm{~N}$ Zeeb Rd, Ann Arbor, MI 48106-1346; 734-761-4700 or 800-521-0600. 